\title{
Medievalista
}

\section{Os mesteirais e o concelho de Lisboa durante o século XIV: um esboço de síntese (1300-1383)}

Craftsmen and the council of Lisbon in the 14th century: an attempt of synthesis (1300-1383)

\section{Bruno Marconi da Costa}

\section{OpenEdition}

\section{Journals}

\section{Edição electrónica}

URL: http://journals.openedition.org/medievalista/1268

DOI: 10.4000/medievalista.1268

ISSN: $1646-740 X$

\section{Editora}

Instituto de Estudos Medievais - FCSH-UNL

\section{Refêrencia eletrónica}

Bruno Marconi da Costa, « Os mesteirais e o concelho de Lisboa durante o século XIV: um esboço de síntese (1300-1383) », Medievalista [Online], 21 | 2017, posto online no dia 01 junho 2017, consultado no dia 19 abril 2019. URL : http://journals.openedition.org/medievalista/1268 ; DOI : 10.4000/ medievalista. 1268

\section{(C) IEM}


Título / Title: Os mesteirais e o concelho de Lisboa durante o século XIV: um esboço de síntese (1300-1383) / Craftsmen and the council of Lisbon in the 14th century: an attempt of synthesis (1300-1383)

Autor(es) / Author(s): Bruno Marconi da Costa

Universidade / University: Universidade Federal do Rio de Janeiro (PPGHC-UFRJ)

Faculdade e Departamento / Unidade de Investigação: Grupo de Estudos Medievais Portugueses (GEMPO)

Código Postal / Postcode: 22776-050

Cidade / City: Rio de Janeiro - RJ

País / Country: Brasil

Email Institucional / Institutional email: brunomarconihistoria@gmail.com

Fonte: Medievalista [Em linha]. Direc. Bernardo Vasconcelos e Sousa. Lisboa: IEM.

Disponível em:

http://www2.fcsh.unl.pt/iem/medievalista/MEDIEVALISTA21/costa2105.html ISSN: 1646-740X

Data recepção do artigo / Received for publication: 31 de Janeiro de 2016

Data aceitação do artigo / Accepted in revised form: 5 de Setembro de 2016 
Os mesteirais e o concelho de Lisboa durante o século XIV: um esboço de síntese (I300-I383) • Bruno Marconi da Costa

\section{Resumo}

Durante o século XIV, o concelho de Lisboa passava por um processo de profunda elitização. Com a intervenção do poder régio, cavaleiros, grandes mercadores, escudeiros, clérigos e homens de letras monopolizavam os cargos concelhios, formando uma verdadeira oligarquia camarária. Convocados por pregões, mesteirais participaram de um número restrito de assembleias gerais do concelho, como forma de legitimação de suas deliberações. O objetivo do presente artigo é apresentar, a partir da documentação chegada até nós, as principais pautas e a forma de convocação desses trabalhadores urbanos, assim como analisar essa presença institucional inserida na experiência social e motivações dos próprios mesteirais durante o século XIV. Consideramos que a marginalização desse grupo social, quando comparada com sua efêmera, porém marcante, inserção política no século XIII, é uma das chaves para a compreensão dos complexos processos de revolta que ocorreram nas décadas de 1370 e 1380 e do ativo protagonismo nos eventos que constituíram a crise dinástica de Avis em 1383-1385.

Palavras-chave: Mesteirais; Concelho; Lisboa; Transição dinástica; oligarquia.

\section{Abstract}

During the 14th century, Lisbon's city council passed through a deep process of elitization. With the interference of the royal power, knights, great merchants, squires, clerics and literati monopolized the council's positions, creating a real oligarchy. Summoned by public announcement, craftsmen took part in a restrict number of the city council's general reunions, as a way to legitimate its decisions. This paper aims to present, through the documents that remain until today, the main council affairs and how this organization summoned those urban workers, as well as analyse this institutional presence inserted in the social experience and motivations of the craftsmen during the 14th century. We consider that the marginalization of this social group, when compared to its transient, though remarkable, political insertion in the 13th century, is one of the keys to the understanding of the complex rebellion processes that happened between 1370 and 1383 and their active protagonism in the events that constitute the Avis dynastic crisis in 1383-1385.

Keywords: Craftsmen; City Council; Lisbon; Dynastic transition; Oligarchy. 


\section{Os mesteirais e o concelho de Lisboa no século XIV : um esboço de síntese (1300-1383) / Craftsmen and the council of Lisbon in the 14 th century: an attempt of synthesis $(1300-1383)$}

\section{Bruno Marconi da Costa}

Durante o século XIV, e principalmente a partir da primeira metade, os trabalhadores urbanos portugueses passavam por grandes dificuldades. A peste assolava a terra, ceifando vidas e sendo um dos fatores da míngua de produção de alimentos. As consecutivas quebras de moeda, mesmo que pensadas com o objetivo de manter numerário no reino, diminuíam o poder aquisitivo da "arraia miúda", fazendo-a trabalhar ainda mais para conseguir pagar pelo mínimo necessário para sobreviver. Além disso, as guerras fernandinas (1369-1370, 1372-1373 e 1381-1382) causaram dano a cidades com seus cercos e incêndios nas desprotegidas zonas peri-urbanas portanto, de população economicamente mais frágil e de menor prestígio. No âmbito político, eram os privilegiados que dominavam os cargos concelhios e as câmaras: cavaleiros, escudeiros, homens com formação universitária e grandes comerciantes constituíam uma oligarquia governativa. Até o momento da crise dinástica que elevou D. João, Mestre de Avis, ao trono, pouco espaço era reservado aos mesteirais nas decisões do poder local.

É sobre essa restrita presença mesteiral no poder concelhio que versa o nosso artigo. Desenvolveremos dois objetivos interligados: o primeiro é apresentar referências disponíveis sobre as convocações dos mesteirais nas reuniões concelhias da cidade de Lisboa, em que estes possuíram uma relevante inserção institucional; o segundo, 
analisar esses documentos de forma a propor uma síntese interpretativa que destaque as principais características dessa atividade política, inserindo-a no contexto histórico das relações de poder que envolviam esse espaço urbano. Intentamos, com isso, contribuir para a compreensão das motivações sócio-políticas que direcionavam esse multifacetado grupo social, de modo a compreender não só a lógica envolvida nas convocações para as assembleias gerais, como também as revoltas ocorridas nas décadas de 1370 e 1380 e o protagonismo dos oficiais dos mesteres na crise dinástica de Avis.

O termo "mesteiral" existe na própria documentação medieval, e refere-se a uma vasta gama de ocupações socioprofissionais. Considerados os meiaos nas sociedades urbanas, ou seja, aqueles em condição intermediária entre os maiores e os menores ${ }^{1}$, essa categoria heterogênea envolve distintos trabalhadores urbanos de indústria ${ }^{2}$ e pequenos comerciantes, desde ourives, sapateiros, ferreiros, correeiros, tanoeiros até almocreves, carniceiros, pescadores e taverneiros. Existia uma hierarquia entre esses diferentes ofícios, como é evidenciado, por exemplo, no Regimento de Procissões de Évora, produzido no século $\mathrm{XV}^{3}$. Esse diferente nível de prestígio social varia de cidade para cidade, apesar de possuir algumas constantes observáveis no conjunto do território português: os que íam à frente participavam de ofícios mais influentes e notáveis da cidade, como ourives e pichileiros, enquanto por último identificamos ofícios pouco prestigiados, como carniceiros e enxerqueiros.

\footnotetext{
${ }^{1}$ Essa divisão social é explicada por Maria Helena da Cruz Coelho em COELHO, Maria Helena da Cruz - "O Estado e as Sociedades Urbanas". in COELHO, Maria Helena da CRUZ; HOMEM, Armando Luís de Carvalho; ALMEIDA, Armando Justino - A Génese do Estado Moderno em Portugal. Ciclo temático de conferências organizado pela Universidade Autónoma de Lisboa no ano lectivo de 1996/1997. Lisboa: Universidade Autónoma Editora, 1997, pp. 269-292. Arnaldo de Sousa Melo destaca que os mesteirais pertencem aos meiaos, mesmo com suas diferenças de capital econômico, político e simbólico, pelo fato de incidir sobre sua maioria as diversas tributações, visto que os menores não possuíam com o que contrubuir e os maiores possuíam diversas isenções. MELO, Arnaldo Rui Azevedo de Sousa - "Os mesteirais e o poder concelhio nas cidades medievais portuguesas (séculos XIV e XV)". Edad Media. Revista de Historia 14 (2013), p. 151.

2 "Se considerarmos a palavra 'indústria' na sua acepção restrita (que é hoje a mais vulgar), de um conjunto de actividades transformadoras implicando produção em larga escala, realizada em fábricas onde trabalham centenas ou milhares de indivíduos, com distinção entre capital e trabalho, dificilmente poderemos falar dela durante os séculos XIV e XV, e muito menos em Portugal. Mas se por 'indústria' aceitarmos um conceito lato, de toda a actividade que concorra para a transformação de matérias-primas e para a produção de riquezas, será então lícito estudá-la no período medieval, mesmo nas suas formas mais limitadas de artesanato doméstico". MARQUES, A. H. de Oliveira - Portugal na Crise dos séculos XIV e XV. Lisboa: Presença, 1987, p. 115.

${ }^{3}$ MARQUES, A. H. de Oliveira - "O trabalho". in A sociedade medieval portuguesa. Lisboa: Sá da Costa, 1976, pp. 137-138.
} 
Diversos autores da historiografia portuguesa teceram comentários sobre a participação política dos mesteirais em Lisboa e suas organizações, baseados em diferentes correntes teóricas e ideológicas. Apesar disso, não se aprofundaram nas especificidades de cada caso, tal como é o objetivo do presente artigo. A meta comum entre eles era construir uma interpretação do processo denominado de "Revolução de Avis", devido a sua importância na definição da própria nacionalidade portuguesa. Na primeira metade do século XX, os pensadores republicanos António Sérgio, Jaime Cortesão e Joel Serrão investigaram, cada um com suas próprias conclusões, a atuação política dos mesteirais no Interregno, principalmente no que diz respeito a sua relação com a nova dinastia. Suas polêmicas envolviam a relação entre a nova dinastia, os grandes comerciantes e a participação da "arraia miúda" nos anos de 1383 a 1385. Enquanto António Sérgio defendia a tese de que esta seria uma "revolução burguesa"4, Jaime Cortesão definia o processo como uma revolução democrática, social, popular e urbana - apresentando a centralidade do elemento mesteiral nesse processo ${ }^{5}$. Já Joel Serrão sustentou que, em um primeiro momento, o caráter da crise social foi realmente popular, contudo foi apropriada nos seus últimos anos por setores da nobreza e da grande burguesia urbana ${ }^{6}$.

Passada a instituição do Estado Novo, intelectuais como Marcello Caetano ${ }^{7}$ e FranzPaul de Almeida Langhanz ${ }^{8}$ estudaram essa questão com afinco, por a considerem uma chave para a revivescência do sistema corporativo, fenômeno ocorrido em Portugal nas décadas de 1930 e 1940. A linha interpretativa desses autores incluía-se em uma história institucionalista de narrativa oficial, que envolvia certas características que serviam à legitimação do regime salazarista sustentadas em uma noção corporativa das origens de uma nação portuguesa. No que diz respeito à "Revolução de Avis", substituíam a noção

\footnotetext{
${ }^{4}$ SÉRGIO, António - Breve interpretação da História de Portugal. Lisboa: Livraria Sá da Costa, 1977, pp. 31-35.

5 CORTESÃO, Jaime - Os factores democráticos na formação de Portugal. Lisboa: Livros Horizonte, 1984, pp. 108-124.

${ }^{6}$ SERRÃO, Joel - O Carácter Social da Revolução de 1383. Lisboa: Livros Horizonte, 1978, pp. 49-61.

${ }^{7}$ CAETANO, Marcelo - A administração municipal de Lisboa durante a $1^{a}$ dinastia. Lisboa: Academia Portuguesa da História, 1981; CAETANO, Marcello - "Prefácio". in LANGHANS, Franz-Paul - A antiga Organização dos Mesteres da Cidade de Lisboa. Lisboa, 1942, pp. XI-LXXV; CAETANO, Marcello - A Crise Nacional de 1383-1385. Subsídios para o seu estudo. Lisboa: Verbo, s.d.

${ }^{8}$ LANGHANS, Franz-Paul de Almeida - "As Antigas Corporações dos ofícios mecânicos e a Câmara de Lisboa". in Separata de Revista Municipal (Lisboa) 7, 8 e 9. Lisboa: Câmara Municipal, 1942, pp. 3-31; LANGHANS, Franz-Paul de Almeida - As Corporações dos Ofícios Mecânicos. Subsídios para a sua História. Vol. I, Lisboa, 1943; LANGHANS, Franz-Paul de Almeida - A Casa dos Vinte e Quatro de Lisboa. Subsídios para a sua História. Lisboa, 1948.
} 
da revolução social e de conflitos sociais com a supervalorização do conceito de "nação", da união das classes contra um invasor externo e na valorização de algumas personalidades como D. João I, Nun’Álvares Pereira e João das Regras como legítimos representantes do povo e defensores da independência portuguesa. Mesmo com todas as críticas que essa perspectiva sofreu até hoje, suas análises pioneiras não podem ser desprezadas para a importância dos avanços das investigações sobre a organização e participação política dos mesteirais medievais portugueses.

Durante as décadas de 1970 e de 1980, com o afrouxamento do Estado Novo, a Revolução dos Cravos e a abertura das universidades a novos estudos de pós-graduação, Portugal inseriu-se em uma efervescente produção historiográfica, permitindo formar novos profissionais especializados em diversos campos da História ${ }^{9}$. Abriu-se espaço para a circulação mais livre de autores marxistas que há muito já produziam, vinculados ao Partido Comunista Português. António Borges Coelho ${ }^{10}$, Álvaro Cunhal ${ }^{11} \mathrm{e}$ Armando Castro ${ }^{12}$ encaixavam os mesteirais em um modelo interpretativo que, apesar de trazer perspectivas interessantes e seguir uma linha oposta à história oficial salazarista, por vezes enquadravam-nos em teleologias esquemáticas e estruturalismos economicistas que anacronicamente transferiam a luta de classes do século XIX para o século XIV, sem a devida revisão teórica e conceitual necessária para a análise do contexto medieval.

Nessa mesma época e continuando nos anos de 1990, outros autores também lançaram seus olhares sobre as atividades políticas dos mesteirais com base em renovações historiográficas da época. São os casos dos estudos socioeconômicos de Maria José Tavares Ferro sobre as revoltas de 1383 e os pobres na Idade Média portuguesa ${ }^{13}$; Maria

\footnotetext{
${ }^{9}$ COELHO, Maria Helena da Cruz - "Municipal Power". in MATTOSO, José (dir.) - Historiography of Medieval Portugal (1950-2010). Lisboa: Instituto de Estudos Medievais, 2011, pp. 209-230.

${ }^{10}$ COELHO, António Borges - A Revolução de 1383. Lisboa: Seara Nova, 1977.

${ }^{11}$ CUNHAL, Álvaro - As Lutas de Classes em Portugal nos Fins da Idade Média. Lisboa: Estampa, 1980.

12 CASTRO, Armando - A Evolução Económica de Portugal dos séculos XII ao XV. Lisboa: Portugália, 1966.

13 FERRO, Maria José Pimenta - "A Revolta dos Mesteirais de 1383". in Actas das III Jornadas Arqueológicas. Lisboa: Associação dos Arqueólogos Portugueses, 1978, pp. 359-363; FERRO, Maria José Pimenta - Pobreza e morte em Portugal na Idade Média. Lisboa: Presença, 1989; FERRO, Maria José Pimenta - "Ricos y Pobres en un Siglo de Crisis". Edad Media - Revista de Historia 4 (2001), pp. 23-36.
} 
Helena da Cruz Coelho, com uma série de trabalhos sobre o poder concelhio e trabalho no medievo ${ }^{14}$; e José Mattoso, que analisa os contrastes entre cidade e campo e polemiza com os autores marxistas ao afirmar a inexistência da possibilidade de uma luta de classes no século XIV ${ }^{15}$.

Mais recentemente, observamos novos estudos, com novos olhares, sobre a organização econômica e política dos mesteirais durante a Idade Média. Destacamos aqui duas Teses de Doutoramento recentemente defendidas: a de Arnaldo Rui de Sousa Melo, que versa sobre o trabalho, organização do espaço e participação política dos mesteirais na cidade do Porto ${ }^{16}$, e a de Mario Sérgio Farelo ${ }^{17}$ que, em sua investigação da oligarquia camarária de Lisboa, possui um capítulo sobre os procuradores dos mesteres. A também

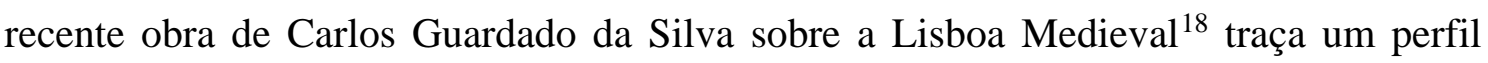
econômico da cidade no fím do século XIII e começo do XIV, baseado na leitura da documentação relativa à compra de tendas por parte do poder régio.

Apesar de esses autores citarem as participações pontuais dos mesteirais no concelho de Lisboa, nenhum deles faz uma análise pormenorizada das características de cada um desses documentos que chegaram até nós - por esse tema não ser objetivo específico de suas respectivas investigações. Para efetuar essa investigação, dividimos o presente artigo em quatro partes. Na primeira, analisaremos a experiência social dos oficiais dos

${ }^{14}$ COELHO, Maria Helena da Cruz; MAGALHÃES, Joaquim Romero - O poder concelhio. Das origens às cortes constituintes. Coimbra: Centro de Estudos e Formação Autárquica, 1986; COELHO, Maria Helena da Cruz - "No palco e nos bastidores do Poder Local". in FONSECA, Fernando Taveira da (dir.) - O poder local em tempo de Globalização. Uma história e um futuro. Coimbra: Centro de Estudos e Formação Autárquica, 2005, pp. 49-74; COELHO, Maria Helena da Cruz - "O povo - a identidade e a diferença no trabalho". in MARQUES, A. H. OLIVEIRA; SERRÃO, Joel (dir.) e COELHO, Maria Helena da Cruz; HOMEM, Armando Luís de Carvalho (coord.) - Nova História de Portugal. Vol. III. Portugal em Definição de Fronteiras. Lisboa: Presença, 1998, pp. 252-308.

${ }^{15}$ MATTOSO, José - "Contrastes entre Cidade e o Campo"; "Luta de classes?". in SARAIVA, José Hermano (dir) - História de Portugal. Lisboa: Alfa, 1983, pp. 159-199; MATTOSO, José - "Revoltas e Revoluções na Idade Média Portuguesa". in Naquele tempo. Ensaios de história medieval. Lisboa: Círculo de Leitores, 2009, pp. 409-425.

${ }^{16}$ MELO, Arnaldo Rui Azevedo de Sousa - Trabalho e Produção em Portugal na Idade Média: O Porto, c. $1320-$ c. 1415. Braga: Universidade do Minho, 2009. Tese de Doutoramento; MELO, Arnaldo Rui Azevedo de Sousa - "Os mesteirais e o poder concelhio...", pp. 149-170; MELO, Arnaldo Rui Azevedo de Sousa - "Os mesteirais no governo urbano do Porto nos séculos XIV e XV". in SOLORZANO TELECHEA, J. A.; BOLUMBURU, B. A. (coord.) - La Gobernanza de la ciudad europea en la Edad Media, Logroño: Centro de Estudios Riojanos, 2011, pp. 323-347.

FARELO, Mário Sérgio - A Oligarquia Camarária de Lisboa (1325-1433). Lisboa: Faculdade de Letras da Universidade de Lisboa, 2008. Tese de Doutoramento.

${ }^{18}$ SILVA, Carlos Guardado da - Lisboa Medieval. A organização e estruturação do espaço urbano. Lisboa: Colibri, 2008. 
mesteres olissiponenses nos séculos XIII e XIV. A seguir, a relação entre o quadro institucional do concelho e os representantes dos mesteres durante o século XIII. Na terceira seção, apresentaremos os documentos do século XIV até o começo da Crise Dinástica que tenham menção à participação de mesteirais em assembleias do concelho. Por fim, destacaremos os assuntos tratados e as modalidades de participação, esboçando uma interpretação sintética sobre o objeto em busca de permanências e rupturas em relação a sua atuação nos acontecimentos que levaram D. João, Mestre de Avis, ao trono português.

\section{A experiência social dos mesteirais de Lisboa nos séculos XIII e XIV ${ }^{19}$}

Depois de um processo de acelerado crescimento que atravessou a totalidade do século XIII, na centúria seguinte Lisboa podia ser considerada a mais importante cidade do reino português. Comparada ao conjunto do Ocidente Medieval, equivaleria a uma cidade de médio porte, de acordo com A. H. de Oliveira Marques ${ }^{20}$. Mesmo com a crise econômica e a peste que assolou todo o território do reino, a cidade continuou crescendo durante a centúria dos Trezentos. Saiu de 14000 habitantes distribuídos por sessenta hectares ao fim do século XIII para o número de 35000 em cento e oitenta hectares amuralhados na década de $1370^{21}$. O fato de Lisboa ter passado pela construção de duas muralhas em menos de um século - a da Ribeira com D. Dinis e a Cerca Fernandina mostra o acelerado desenvolvimento de seu espaço urbano.

Os mesteirais tiveram certo protagonismo nesse processo histórico de transformações econômicas. Maria Helena da Cruz Coelho aponta a complexificação das atividades manufatureiras no decorrer do século XIII e XIV, fruto de um aumento populacional e necessidade de uma contínua especialização:

\footnotetext{
19 Trabalhamos mais aprofundadamente os fatores constitutivos de uma experiência comum dos mesteirais portugueses e como eles podem interferir em suas atividades políticas, baseado em um arcabouço teórico de E. P. Thompson, em COSTA, Bruno Marconi da - "A experiência social dos mesteirais medievais portugueses - uma abordagem thompsoniana". Roda da Fortuna - Revista Eletrônica sobre Antiguidade e Medievo vol. 3, 1 (2014), pp. 221-241. Para o conceito de experiência social, THOMPSON, E. P. - A Miséria da Teoria ou um planetário de erros: uma crítica ao pensamento de Althusser. Rio de Janeiro: Zahar, 1981, p. 15; pp. 15, 134 e 180-200.

${ }^{20}$ MARQUES, A. H. de Oliveira - "Lisboa Medieval: uma visão de conjunto". in Novos Ensaios de História Medieval Portuguesa. Lisboa: Presença, 1988, p. 82.

${ }^{21}$ Tal como apresentado por Oliveira Marques e corroborado por Carlos Guardado da Silva em SILVA, Carlos Guardado da - Lisboa Medieval...
} 
"O ferreiro que tudo fabricava deu lugar ao ferrador, ao alfageme, ao armeiro, ao cutileiro; os originais curtidores e peliteiros multiplicaram-se em correeiros, seleiros e albardeiros; os carpinteiros acompanharam-se dos calafates e tanoeiros; e tantos mais, que com obras de maior qualidade desejavam abarcar os mercados locais ou mais longínquos" 22 .

Esses trabalhadores espalhavam-se por Lisboa com suas tendas e casas, organizando-se em arruamentos, de uma maneira mais flexível do que a obrigatoriedade concelhia que os tempos modernos ditavam. A toponímia medieval ajuda-nos a identificar a sua fixação por toda a urbe - contudo, estavam majoritariamente concentrados na região da Ribeira Ocidental, ou seja, a zona considerada a Baixa de hoje ${ }^{23}$. Esta era a zona mais dinâmica da cidade, o espaço economicamente vivo no qual comerciantes e artífices compartilhavam o viver citadino.

Uma das facetas dessa complexificação é o crescimento do número de associações de assistência religiosa. As chamadas confrarias eram instituições de solidariedade que ofereciam ajuda não só a questões da alma, mas também caridade aos males do corpo sofridos pelos mais pobres. Nas palavras de Maria Helena da Cruz Coelho,

\begin{abstract}
"O homem medieval, homem de rua, de espaços abertos e vida ao ar livre, de relações várias com outros homens, vai delinear a confraria como um reforço das cadeias relacionais de família, trabalho, devoção, ajuda e sufrágio. A instituição confraternal concebe-se com uma orgânica e ritualização que convidam à vida em comum. Vida em comum no interior
\end{abstract}

\footnotetext{
${ }^{22}$ COELHO, Maria Helena da Cruz - "O povo - a identidade e a diferença no trabalho...", p. 281.

23 "[O] Porto de Lisboa, pulsando continuadamente no movimento ritmado e alternante da chegada das mercadorias, da partida das mercadorias, era o motor que fazia circular aqueles capitais, que insuflava vida - uma vida intensa e variada - a toda a cidade. E a Ribeira, ponto de apoio às atividades portuárias, era o espaço onde essa vida palpitava com maior intensidade, onde começava a organizar-se e a diferenciar-se, de onde irradiava para todos os lados. Mas era também à Ribeira que tudo afluía, onde mais se concentravam pessoas e bens, atividades profissionais e até lúdicas." GONÇALVES, Iria - "Na Ribeira de Lisboa, em finais da Idade Média". in Um Olhar sobre a Cidade Medieval. Cascais: Patrimonia, 1996, p. 62.
} 
da confraria, vida em comum no mundo externo e, finalmente, vida em comum no passamento e irmandade de vivos e mortos" 24 .

No caso olisiponense, pode apresentar-se, como exemplo, o caso dos ferreiros, que organizaram uma confraria datada pelo menos de $1229^{25}$. De acordo com Maria José Ferro Tavares, Lisboa foi a cidade com o maior número de confrarias de mesteirais em comparação às demais do reino português: mercadores, bombardeiros, peliteiros, ourives, tanoeiros, pedreiros e carpinteiros, barbeiros e caldeireiros, hortelãos, carpinteiros do mar, pescadores do alto, chincheiros, sapateiros de correia, alfaiates, entre diversas outras ${ }^{26}$.

Além da ajuda, é importante colocar em evidência algo subjacente às confrarias: a sociabilidade. Com um calendário de reuniões, uma forte hierarquia interna e estatutos que definiam o cotidiano de seus membros, o auxílio espiritual comportava-se também como uma congregação de pessoas com experiências sociais semelhantes, um catalizador para uma consciência comum. Em um período de crise aprofundada, quando trabalhadores de um mesmo ofício sofrem igualmente com uma estrutura econômica que os coloca em situações de fragilidade social, encontrar-se com outros que partilhavam da mesma vivência sob a égide da caritas cristã criava um vínculo entre esses indivíduos. Assim, as confrarias eram efetivas, essenciais para estabelecer laços sociais entre indivíduos e famílias dos mesmos ofícios, conferindo a eles uma possibilidade de uma cultura política de ação coletiva ${ }^{27}$.

\footnotetext{
${ }^{24}$ COELHO, Maria Helena da Cruz - "As confrarias medievais portuguesas: espaços de solidariedades na vida e na morte". in Atas da XIX Semana de Estudios Medievales. Confradías, gremios, solidaridades en la Europa Medieval. Estella: Gobierno de Navarra, Departamento de Educación y Cultura, 1992, p. 162. ${ }^{25}$ PRADALIÉ, Gérard - Lisboa: da Reconquista ao fim do século XIII. Lisboa: Palas, 1975, p. 148.

${ }^{26}$ TAVARES, Maria José Pimenta Ferro - Pobreza e morte em Portugal na Idade Média..., pp. 110-111.

${ }^{27}$ Por "ação coletiva", utilizamos o conceito desenvolvido por Charles Tilly em TILLY, Charles - From Mobilization to Revolution. Michigan: CRSO Working Paper, 1977. Esse conceito foi também aplicado por Jelle Haemers para analisar as formas pacíficas de intervenção política dos mesteirais de Flandres, em HAEMERS, Jelle - "Ad petitionem burgensium. Petitions and peaceful resistane of craftsmen in Flanders and Mechelen (13th-16th centuries)". in TELECHEA, J.; BOLUMBURU, B; HAEMERS, J. (ed) - Los grupos populares en la ciudad medieval europea. La Rioja: Instituto de Estudios Riojanos, 2014, p. 380.
} 


\section{Antecedentes: os mesteirais e o concelho de Lisboa no século XIII}

As participações dos mesteirais em assembleias do concelho durante os séculos XIII e XIV devem ser analisadas sob as diversas possibilidades de intervenção nas decisões. Dentro dessa diferenciação, Arnaldo de Sousa Melo construiu uma tipologia para a cidade do Porto: existem aquelas nas quais os mesteirais participam integrando o corpo da assembleia, ou seja, o conjunto da comunidade urbana junto a outros vizinhos e homens bons com igual capacidade deliberativa; e aquelas nas quais os mesteirais de um ou mais ofícios estão presentes na qualidade de representantes como um grupo específico, porém apenas com caráter consultivo ou de acordo entre distintas partes de um litígio ${ }^{28}$.

A primeira referência que possuímos a um mesteiral no concelho da cidade recua ao ano de 1244, quando em uma transação um alfaiate chamado Vicente Pais é mencionado como testemunha e referido como um homem bom ${ }^{29}$. Apesar de não podermos aferir exatamente qual a frequência com que esse indivíduo participava e as especificidades da sua inserção política, é razoável afirmar que não seria uma prática estranha que um artífice estivesse nas reuniões da assembleia de vizinhos. A partir desse momento, os mesteirais são chamados para participar das reuniões concelhias, como a assembleia magna que ocorre com a presença de D. Dinis em $1285^{30}$.

Nesta reunião, nomeados pelo tabelião João Mendes, após divulgação feita por pregoeiros e porteiros a mando do alcaide e dos alvazis da cidade, estavam presentes, além dos donos dos cargos acima citados, oito cavaleiros, cinco mercadores, dezesseis peliteiros, dezesseis alfaiates, dez pescadores. E constavam entre os participantes "outros muitos caualeiros, escudeiros, crerigos, cidadãos, mercadores, alfayates,

\footnotetext{
${ }^{28}$ MELO, Arnaldo Rui Azevedo de Sousa - "Os mesteirais no governo urbano do Porto...”, pp. 338-341.

${ }^{29}$ PRADALIÉ, Gérard - Lisboa: da Reconquista..., p. 91.

30 Analisamos essa assembleia em nossa Dissertação de Mestrado: COSTA, Bruno Marconi da $-A$ burguesia concelhia da Lisboa de D. Dinis - um estudo comparativo das suas relações com o poder monárquico (1279-1325). Rio de Janeiro: Universidade Federal do Rio de Janeiro, 2013. Dissertação de Mestrado. Disponível em www.academia.edu/3997194/A_burguesia_concelhia_da_Lisboa_de_D._Dinis_um_estudo_comparativo _de_suas_rela\%C3\%A7\%C3\%B5es_com_o_poder_mon\%C3\%A1rquico_1279-1325_
} 
peliteyros, çapateiros, correiros, \& ferreiros, que forom chamados, \& juntados a esta cousa" ${ }^{31}$.

A matéria dessa ampla e plural reunião de vizinhos com a autoridade maior do reino dizia respeito a uma série de agravos que D. Afonso III, pai de D. Dinis, havia feito à cidade. Lourenço Escola, o alcaide da cidade, entregou um documento produzido pela assembleia de vizinhos do concelho, envolvendo a cobrança indevida de impostos por parte dos oficiais régios, a intervenção régia sobre a justiça ministrada pelos alvazis e alcaide da cidade e a apropriação de terrenos nos rossios pelos oficiais do rei.

Marcelo Caetano considera que João Mendes teria dado ênfase à presença dos mesteirais devido ao seu caráter "insólito" 32. Já Miguel Gomes Martins apresenta-nos uma diferente interpretação, afirmando que a evidência depositada nessa categoria social diria respeito a uma necessidade de sublinhar a pluralidade dos agentes envolvidos naquelas questões, como uma forma de garantir a legitimidade e a importância que aquele evento tinha para a vida concelhia ${ }^{33}$. Maria Helena da Cruz Coelho afirma que apesar de as reivindicações apresentadas dizerem respeito aos mesteirais, estas "mais se reportavam aos interesses dos mercadores" 34 .

Na última década do século XIII, os mesteirais conseguiram uma maior organização no que diz respeito à participação desse grupo social no concelho. Em uma carta régia datada de 1298, D. Dinis delibera sobre o pagamento de impostos que os habitantes de Lisboa deveriam efetuar, devido à guerra ocorrida com Castela anos antes. De acordo com o documento, o concelho costumava se reunir para discutir a questão com seus homens bons e "dois homens bons de cada mester" ${ }^{35}$, o que mostra uma mobilização por parte desse grupo social para garantir que sua voz fosse ouvida sobre esse tema específico.

\footnotetext{
${ }^{31}$ BRANDÃO, Frei Francisco -“ESCRITVRA XVIII". in Monarchia Lusitana. Quinta Parte. Lisboa: Officina de Paulo Craeesbeck, 1650, fls. 314v-315v.

${ }^{32}$ CAETANO, Marcelo - A administração municipal de Lisboa..., p. 37.

${ }^{33}$ MARTINS, Miguel Gomes - "O Concelho de Lisboa durante a Idade Média. Homens e Organização Municipal (1179-1383). in Cadernos do Arquivo Municipal de Lisboa. Lisboa: Câmara Municipal. Série I, 7 (2004), p. 71.

${ }^{34}$ COELHO, Maria Helena da Cruz - "O povo - a identidade e a diferença no trabalho...”, p. 284.

${ }^{35}$ DOCUMENTOS PARA A HISTÓRIA DA CIDADE DE LISBOA. Livro I de Místicos de Reis: Livro II dos Reis D. Dinis, D. Afonso IV, D. Pedro I. Lisboa: Câmara Municipal de Lisboa, 1947, doc. 3: 113.
} 
A discordância entre os homens bons do concelho dizia respeito à forma de pagamento: enquanto os cavaleiros queriam que este fosse efetuado seguindo as "cavalarias e apeoarias", ou seja, de acordo com o status jurídico sócio-militar definido pelo foral da cidade, os peões defendiam que o pagamento fosse feito “às valias", ou seja, de acordo com a renda - quem recebesse mais, pagava mais. Tal debate não chegou a um consenso, o que levou a D. Dinis a intervir na autonomia concelhia e decidir, tomando o lado da elite urbana lisboeta: cavaleiro pagaria como cavaleiro e peão como peão.

Na mesma carta, D. Dinis usa a autoridade do poder régio para definir o método de reuniões do concelho, de maneira a evitar novas contendas e discordâncias. Assim, decide que sejam chamados apenas os homens bons da cidade, marginalizando os mesteirais das deliberações da assembleia. Inaugura, assim, um processo de elitização e oligarquização do concelho de Lisboa que perduraria quase a totalidade do século XIV. Os mesteirais eram, de fato, convocados para algumas reuniões, como veremos a seguir, porém jamais com a mesma organização e voz política que observamos ao fím do século XIII. Essa lógica só seria rompida, ainda que apenas provisoriamente, durante a Crise Dinástica de Avis.

\section{As participações dos mesteirais no concelho de Lisboa durante o século XIV}

Durante o conjunto do século XIV, pode ser observada uma crescente especialização no governo urbano. Dessa forma, as assembleias de vizinhos, abertas e alargadas, ocorridas no adro da Sé, foram gradativamente sendo substituídas, principalmente a partir da década de 1330, por reuniões fechadas na câmara da vereação, dentro do Paço do Concelho $^{36}$. Uma oligarquia camarária forma-se, com forte relação com o poder régio, e a presença dos mesteirais nas assembleias torna-se mais raras. Essas reuniões serão objeto de nossa análise a seguir.

O corpus no qual destacamos os documentos a seguir encontra-se majoritariamente publicado na coletânea Documentos para a História da Cidade de Lisboa. Utilizamos, da mesma forma, alguns códices que podem ser localizados no Arquivo Histórico

\footnotetext{
${ }^{36}$ Sobre a oligarquia concelhia de Lisboa, remetemos aos trabalhos de Miguel Gomes Martins e à Tese de Doutoramento de Mario Sérgio Farelo. MARTINS, Miguel Gomes - "O Concelho de Lisboa durante a Idade Média..."; FARELO, Mário Sérgio - A Oligarquia Camarária de Lisboa...
} 
Os mesteirais e o concelho de Lisboa durante o século XIV: um esboço de síntese (I300-I383) • Bruno Marconi da Costa

Municipal de Lisboa, nomeadamente no Livro I de Sentenças, assim como algumas fontes avulsas guardados no Arquivo Nacional da Torre do Tombo (ANTT). Não há abaixo, portanto, nenhuma fonte histórica que não seja conhecida pela historiografia portuguesa - apenas foram apresentadas e sistematizadas da forma que propomos, de maneira a desenvolver uma análise específica sobre o objeto.

A primeira referência à presença de mesteirais em uma assembleia no século XIV aconteceu no ano de 1304. O concelho reuniu-se com o objetivo de deliberar sobre a outorga de um campo na Ribeira de Lisboa a Domingos de Gaia e sua mulher, Marinha Eanes. A condição para a doação seria que o outorgado fosse responsabilizado pela construção da muralha naquele terreno. Participaram dessa assembleia Gonçalo Eanes Lobo, alcaide; Nuno Fernandes Cogominho, Martim Rodrigues e João Domingues de Arruda, alvazis; Rui de Lemos e Bartolomeu Domingues, alvazis dos ovençais; Lourenço Peres e Domingos Martins, almoxarifes; e muitos homens bons de cada mester, todos chamados e apregoados ${ }^{37}$.

A próxima menção para os mesteirais que temos acesso refere-se a uma carta régia do ano de 1314, quando ourives e outros ofícios "que vivem de peso" reivindicam que a almotaçaria estaria levando em impostos mais do que era devido. Por outro lado, Paulo Domingues (procurador do concelho na corte) e Afonso Eanes defenderam que a cobrança estava de acordo com os privilégios e o foro outorgados por reis anteriores ao concelho de Lisboa. Dessa forma, D. Dinis resolve que o concelho deve se reunir com os homens bons ali referidos e decidir qual a forma mais adequada para efetuar a cobrança desses impostos, de maneira a não ir contra os costumes que regiam a cidade $^{38}$.

A referência seguinte a mesteirais sendo convocados para uma assembleia concelhia foi no ano de 1333, na qual foi lido um documento de D. Afonso IV sobre um conflito que envolvia, de um lado, Domingos Peres e sua mulher e, do outro, o concelho. O casal havia construído algumas casas no Rossio, espaço aberto de propriedade concelhia que

\footnotetext{
${ }^{37}$ A.N.T.T., Mosteiro de S. Dinis de Odivelas, liv. 19, fl. 6-8.

${ }^{38}$ DOCUMENTOS PARA A HISTÓRIA DA CIDADE DE LISBOA. Livro I de Místicos de Reis..., pp. 127128.
} 
Os mesteirais e o concelho de Lisboa durante o século XIV: um esboço de síntese (I300-I383) • Bruno Marconi da Costa

não deveria ser ocupado. Assim, o rei decide, após inquirições, que os dois deveriam ceder as casas ao concelho em troca de 800 libras. Em translado do ano de 1339, essa carta foi apresentada e publicada, após apregoamento, perante os alcaides, juízes, muitos homens bons, cavaleiros, cidadãos e mesteres da cidade ${ }^{39}$.

No ano de 1336, D. Afonso IV outorga ao concelho da cidade o pagamento de sisas sobre a venda do vinho, contanto que estas não agravassem os pobres. Após apregoamento, o concelho reuniu no paço diversas testemunhas, entre elas o alcaide Gil Vasques, o alvazis dos feitos do crime Pedro Anes Palhavã, Martim de Rates, tesoureiro do concelho, o almirante-mor Manuel Pessanha, Pedro Esteves e Martim Domingues, almoxarifes, além de "outros muitos cavaleiros, cidadãos e muytos mesteyrais da dita cidade". Foi decidido, com a presença destes, que a sisa seria arrendada por dois anos ${ }^{40}$.

Em 1342, no dia 12 de março, a população de Lisboa foi convocada por pregão para a eleição de seus alvazis e oficiais, "como de seu costume", e escolheram Afonso Martins Alvernaz como procurador do concelho. Estavam presentes o alcaide Rui Fafes, os alvazis gerais, dos feitos do crime e dos ovençais, vedores, procuradores, cavaleiros e muitos outros ditos "homens-bons, cavaleiros, cidadãos e mesteirais"41.

Apesar de não se tratar propriamente de uma participação de mesteirais na assembleia concelhia, destacamos aqui uma fonte que trata de um assunto referente à relação entre carniceiros e os magistrados locais. Em 1347, D. Afonso IV envia uma carta ao concelho, direcionada a seus alvazis e vereadores, versando sobre a perseguição que os carniceiros vinham sofrendo na cidade. $\mathrm{O}$ documento nomeia nove carniceiros que se fazem presentes junto ao rei contra o concelho pois, alegam eles, são presos sem motivo e sem serem ouvidos às ordens dos juízes da cidade. Nesse processo, são forçados a arcar com os custos da carceragem. Reclamam, ainda, um preço justo para as carnes, visto que os valores tabelados pelos almotacés davam a eles prejuízos. O rei então decide que os carniceiros devem dar as carnes que são pedidas pelo concelho de acordo

\footnotetext{
${ }^{39}$ DOCUMENTOS PARA A HISTÓRIA DA CIDADE DE LISBOA. Livro I de Místicos de Reis..., pp. 183186.

${ }^{40}$ DOCUMENTOS PARA A HISTÓRIA DA CIDADE DE LISBOA. Livro de Místicos do Rei D. Fernando. Lisboa: Câmara Municipal de Lisboa, 1948, pp. 13-15.

${ }^{41}$ AML-AH, Livro I de Sentenças, n. 3
} 
Os mesteirais e o concelho de Lisboa durante o século XIV: um esboço de síntese (I300-I383) • Bruno Marconi da Costa

com o que é cobrado por costume pela almotaçaria, porém apenas podem ter seus bens confiscados, sofrer qualquer agravo físico ou serem presos se os alvazis e vereadores da cidade considerarem "que he mester com direyto" 42 .

A referência seguinte aos mesteirais data do ano de 1352, quando o concelho é convocado para debater o futuro de um terreno de sua propriedade em Oira, onde o rei possuía suas galés. Esse campo é negociado com o poder régio em troca da quitação de dívidas referentes à jugada do pão produzido no Alqueidão, vila localizada no termo de Lisboa, no valor de 30 moios de pão meado. Convocados por apregoamentos compareceram ao concelho os alvazis, o procurador, vereadores, tesoureiros, homens bons e mesteirais ${ }^{43}$.

Com o objetivo de fazer reparos aos muros e portões da cidade, no ano de 1355 o concelho lançou novas sisas sobre o vinho durante um ano. $\mathrm{O}$ documento explicita que devido ao fato de o concelho comprar o pão e revendê-lo a preço mais barato, acabou por se endividar e precisava de novas fontes de rendimento para a manutenção das defesas urbanas - a única possibilidade seria o imposto sobre o vinho. Estão presentes para essa deliberação, no adro da Sé, indivíduos que detinham cargos concelhios (o alcaide João Peres, alvazis, vereadores, procuradores, almoxarifes), além de escudeiros, cavaleiros e "muitos homens bons da cidade". Quatro mesteirais são nomeados: os alfaiates João Eanes e João Vicente e os ourives Afonso Eanes e Francisco Eanes ${ }^{44}$.

Em nova assembleia ocorrida no ano de 1362, dessa vez com a mediação de D. Pedro, a pauta é novamente a produção de vinho, contudo refere-se a um acordo entre os rendeiros (Vasco Lourenço, Afonso de Água e Diogo Domingues) e o concelho. A contenda surge devido ao fato de os rendeiros se sentirem injustiçados pelas sisas cobradas pelo concelho. De tal forma, D. Pedro quita o que era devido de parte a parte, tanto o que os rendeiros deviam para o concelho, quanto o que os vizinhos deviam para os rendeiros. Para esse acordo reuniram-se, além dos referidos rendeiros, vassalos do

\footnotetext{
${ }^{42}$ DOCUMENTOS PARA A HISTÓRIA DA CIDADE DE LISBOA. Livro I de Místicos de Reis..., pp. 191193.

${ }^{43}$ A.N.T.T., Gav. XIII, maç. 1, n. 25 e Livro $2^{\circ}$ dos Direitos Reais, fl. 272v.

${ }^{44}$ DOCUMENTOS PARA A HISTÓRIA DA CIDADE DE LISBOA. Livro de Místicos do Rei D. Fernando..., pp. 23-25.
} 
Os mesteirais e o concelho de Lisboa durante o século XIV: um esboço de síntese (I300-I383) • Bruno Marconi da Costa

rei, alvazis, vereadores, procurador do concelho, dizimeiro da alfândega, mercadores e outros homens bons e dos mesteres, convocados por pregão. Um mesteiral é nomeado na lista de testemunhas, Afonso Martins, ourives, junto ao oligarca Vasco Afonso Carregueiro e o escrivão Fernando Airas ${ }^{45}$.

Por fim, a última reunião com presença de mesteirais que ocorreu no concelho da cidade diz respeito à eleição do provedor do hospital do Conde D. Pedro, no ano de 1364. Depois da morte de Pedro Esteves, provedor nomeado pelo próprio Conde D. Pedro e Teresa Eanes, os alvazis da cidade passaram a administrar a capela, o hospital e as posses, tal como ordenado em testamento. Dessa forma, elegeram um novo provedor, João Cravo, que também morrera. Assim, cabia indicar um novo nome para o cargo, sendo decidido ser o cidadão e alvazil dos feitos dos crimes, Vasco Afonso Carregueiro. Para essa reunião, foi feita uma convocação por apregoamento, e compareceram o alcaide do castelo, Álvaro Gonçalves, acompanhado por alvazis, escudeiros, cavaleiros, tesoureiro do concelho, vereadores, juízes e outros homens bons, fidalgos e mesteirais de Lisboa $^{46}$.

Depois disso, a única referência que temos de uma nova menção à participação dos mesteirais junto ao concelho ou em reivindicações expressas ao poder régio acontece somente no período no qual D. João é Regedor e Defensor do reino, no dia $1^{\circ}$ de abril de 1384, quando entregam uma série de reinvidicações para o Mestre de Avis. Este evento é central para a construção de uma interpretação sobre a lógica que imperava na participação política dos mesteirais, assim como as revoltas que ocorreram nas décadas de 1370 e 1380.

\section{As participações dos mesteirais no concelho de Lisboa durante o século XIV: 1.}

\section{Assuntos}

A exposição a seguir será dividida em duas partes: a primeira procura construir uma interpretação sobre o conteúdo dos temas sobre os quais os mesteirais eram chamados a testemunhar ou participar em suas decisões. A segunda, as modalidades e significados

${ }^{45}$ DOCUMENTOS PARA A HISTÓRIA DA CIDADE DE LISBOA. Livro I de Místicos de Reis..., pp. 3337.

${ }^{46}$ A. N. T. T., Livro I do Hospital do Conde D. Pedro, n. 34 (cópia). 
dessa participação, ou seja, como eram chamados e qual a capacidade de intervenção desses agentes sociais sobre a instituição concelhia nos casos acima citados e como essa presença poderia ser inserida em um processo histórico maior, envolvido no contexto específico do último quartel da centúria.

No âmbito dos assuntos das assembleias nas quais os mesteirais são convocados, parece-nos que estes estão presentes no que diz respeito a questões referentes ao governo e abastecimento da cidade - preocupação central da instituição concelhia desde a sua formação originária. Assim, o conjunto social é convocado por apregoamento para que um imposto sobre a venda do vinho $(1336,1355)$ ou em um acordo com os rendeiros (1362) seja colocado em prática, tanto para quitar dívidas quanto para arcar com custos da responsabilidade do concelho no que tange à defesa da cidade.

Os interesses dos mesteirais por vezes entravam em choque com aqueles da governação concelhia, como podemos observar no apelo feito pelos carniceiros a D. Afonso IV em 1347. Destacamos aqui esse caso, apesar de não se tratar de participação política na assembleia concelhia, porque não é um conflito exclusivo de Lisboa. Adelaide Millán da Costa expressa que nas vereações do Porto do século XV existia, de forma bastante semelhante, esse enfrentamento entre carniceiros buscando o fim de seus prejuízos e magistrados do concelho preocupados com o abastecimento da cidade ${ }^{47}$. Observamos como, por não terem voz ativa no concelho, tal como possuíram por um escasso período no fim do século XIII, restava o apelo ao poder régio como forma de resolução do impasse social causado por esse conflito.

Outro assunto em que o corpo social urbano era convocado à participação diz respeito às negociações referentes às propriedades do concelho, em que precisariam ter alguma ação - geralmente, pagar. Evidenciamos aqui as casas na Ribeira, região

\footnotetext{
${ }^{47} \mathrm{O}$ conflito é, de fato, semelhante - fruto de um estatuto alheio a privilégios por parte dos carniceiros na hierarquia social. "As actas consignam as razões de ambas as partes: do lado do bem comum, assumido pelo governo municipal, alegava-se que a irregularidade do abastecimento à cidade decorria directamente das possibilidades de os carniceiros obterem lucro, prova acabada de má fé; o objectivo era conseguir o compromisso da colocação semanal no mercado de um número fixo de cabeças de gado; por seu lado, os carniceiros rejeitavam os quantitativos propostos, atendendo ao elevado custo dos animais, às deslocações que eram obrigados a fazer para os adquirirem e à canalização do gado para Castela." COSTA, Adelaide Pereira Milàn da - "Traços da Interacção Conflitual na Sociedade Portuense de Quatrocentos". in Actas das Jornadas Inter e Pluridisciplinares. A Cidade, vol. 1, Lisboa: Universidade Aberta, 1993, p. 158.
} 
economicamente ativa da cidade, cedidas a um casal no ano de 1304 contanto que estes fizessem o compromisso de construir a muralha que passaria por aquela região e que já havia começado sua construção dez anos antes. Da mesma forma, os mesteirais se fazem presentes na troca do terreno em Oira pela quitação de dívidas com o poder régio. De grande importância também é a referência às casas construídas ilegalmente no Rossio, área que desperta interesse do conjunto da população da cidade desde o século XIII, como podemos observar na assembleia magna ocorrida em 1285.

Identificamos, de forma mais casuística do que estrutural, a participação de mesteirais na eleição de alguns magistrados - como é o caso da eleição para procurador, alvazis e oficiais do concelho em 1342 e do provedor do hospital do Conde D. Pedro em 1364. Mesmo com o documento atestando que para essa reunião o concelho era convocado como testemunha por costume, essa presença dificilmente poderia ser chamada de regra. É provável que estas assembleias respondessem a uma demanda específica, restrita a um contexto pontual e temporalmente limitado, e não se apresentam como uma realidade estrutural da inserção política desse grupo social na cidade.

\section{As participações dos mesteirais no concelho de Lisboa durante o século XIV: 2. Modalidades e significados da participação}

No âmbito da análise da forma de participação dos mesteirais, não podemos separar esses acontecimentos da cultura política vigente compartilhada na ordem jurídica das elites dirigentes das cidades medievais ${ }^{48}$. Ao seguirmos essa linha interpretativa, os mesteirais, apesar de por vezes serem nomeados, são tratados pelas autoridades concelhias apenas como parte de um grupo maior que envolve a totalidade da urbe, sem possuírem uma representação especial ou organizada em torno de seus próprios interesses. Portanto, os membros do concelho podem deliberar com a legitimidade que a

\footnotetext{
${ }^{48}$ Em relação à cultura política compartilhada entre a Coroa e as elites urbanas no contexto das cortes portuguesas, referimo-nos ao artigo de Adelaide Millán da Costa: COSTA, Adelaide Pereira Millán da -"A cultura política em ação. Diálogos institucionais entre a Coroa e os centros urbanos em Portugal no século XIV". in En la España Medieval vol. 36 (2013), pp. 9-29; sobre a ordem jurídica corporativa vigente na Idade Média europeia, António Manuel Hespanha escreve: "o pensamento medieval sempre se manteve firmemente agarrado à ideia de que cada parte do todo cooperava de forma diferente na realização do destino cósmico. Por outras palavras, a unidade da criação não comprometia, antes pressupunha, a especificidade e irredutibilidade dos objectivos de cada uma das 'ordens da criação' e, dentro da espécie humana, de cada grupo ou corpo social". HESPANHA, António Manuel - Panorama Histórico da Cultura Jurídica Europeia. Sintra: Europa-América, 1997, pp. 59-62.
} 
Os mesteirais e o concelho de Lisboa durante o século XIV: um esboço de síntese (I300-I383) • Bruno Marconi da Costa

representatividade garantida por todo o corpo social urbano, que envolvia mesteirais, cavaleiros, escudeiros, mercadores, cidadãos, magistrados e demais autoridades concelhias - tal como apresentou-nos a tipologia de Arnaldo de Sousa Melo.

Se, por um lado, essa interpretação explica o porquê de os mesteirais serem convocados por pregão pela oligarquia para as assembleias concelhias, por outro ela não pode ser considerada totalizante para uma análise da complexidade de motivações que envolve o tecido social urbano de uma cidade tão plural quanto Lisboa. Ao ampliarmos a visão para o conjunto de experiências sociais vivenciadas por esses mesteirais, podemos considerar válida uma interpretação que não considere essa presença nas assembleias apenas uma forma de legitimação, mas também uma relação de forças em busca de voz política institucionalizada por parte desse grupo social, marginalizado do processo decisório concelhio, com a oligarquia urbana lisboeta.

Para sustentar essa abordagem, é necessário ampliar o nosso olhar para inserir essas assembleias na rede de causalidades que levaram às revoltas dos mesteirais nas décadas de 1370 e 1380 e ao protagonismo desse grupo social no desencadeamento dos eventos da Crise Dinástica de Avis. A versão mais consolidada desses eventos está expressa na Crónica de D. Fernando, na qual Fernão Lopes restringe a causa para o levantamento popular liderado pelo alfaiate Fernão Vasques em Lisboa ao casamento do rei com D. Leonor Teles, mulher casada com seu vassalo ${ }^{49}$. Em uma abordagem distinta dessa que seria a mais tradicional na historiografia portuguesa, Maria José Ferro Tavares identifica que os mesteirais, organizados em "uniões populares", teriam suas motivações em questões socioeconômicas, principalmente em relação à quebra de moedas e às devastações provocadas pela política belicista do monarca em relação a Castela ${ }^{50}$.

Parece-nos, porém, que a marginalização dos mesteirais do processo deliberativo do concelho surge como mais uma variável a ser acrescentada nessa rede de causalidades. Isso aparece de forma destacada se traçarmos uma continuidade entre essas uniões e revoltas populares do reinado de D. Fernando com a atuação da arraia miúda na Crise

\footnotetext{
${ }^{49}$ LOPES, Fernão - Crónica de D. Fernando. Biblioteca de Clássicos Portuguezes. Lisboa: Escriptorio, 1895, vol 1, p. 191.

${ }^{50}$ FERRO, Maria José Pimenta - A Revolta dos Mesteirais de 1383..., pp. 359-363.
} 
Dinástica, analisando a carta outorgada em 1384 por D. João, à época Regedor e Defensor do Reino, contendo demandas dos "mesteirais, povoadores e moradores da nossa nobre cidade de Lisboa"51. Concomitantemente às batalhas entre o exército de apoiadores de D. João Mestre de Avis contra D. Juán de Castela, que já se encontrava em território português, os trabalhadores urbanos apresentaram uma série de reivindicações ao futuro monarca que apoiavam.

O documento consta de uma lista de nove reivindicações, todas elas acatadas pela autoridade do defensor e regedor de Portugal. Entre elas, encontramos: um pedido de afastamento de Álvaro Gonçalves do conselho de D. João, por acreditarem que este seria leal à rainha $\mathrm{D}$. Leonor; a presença de dois homens bons letrados, nascidos e pagos pelo concelho de Lisboa, no mesmo conselho; que nenhuma decisão ou eleição de magistrados seria feita no concelho da cidade sem "a menos que dous homes bõos de cada hии mester sejam chamados" (grifo nosso); o concelho deveria ter autonomia para decidir seus próprios funcionários, sem a intervenção régia; aos mesteirais deveria ser garantida a isenção de oferecer aposentadoria aos oficiais e nobres que por lá passassem, que deveriam ser direcionados para os mosteiros, paços e judiarias; e por fim, que os impostos sejam pagos às valias, ou seja, que os ricos paguem mais e os pobres paguem menos.

Essa fonte mostra uma certa organização dos mesteirais, principalmente no que diz respeito à garantia de espaço para a sua participação nas assembleias do concelho e sua autonomia em relação ao poder régio. O modelo de representação, "dois homens bons de cada mester", é observado anteriormente em outros lugares da Europa Ocidental ${ }^{52}$ e

\footnotetext{
51 A.N.T.T., Chancelaria de D. João I, Livro I, fls $21 \mathrm{v}$ a 22v, disponível em VIEGAS, Valentino Lisboa, A Força da Revolução (1383-1385). Lisboa: Livros Horizonte, 1985, pp. 218-220.

52 Destacamos como exemplo o caso de Oviedo, que possuía a representação de dois de cada mester já no ano de 1262, referido em MONSALVO ANTÓN, José María - "Los artesanos y la política en la Castilla medieval. Hipótesis acerca de la ausencia de las corporaciones de oficio de las instituiciones de gobierno urbano". in CASTILLO, S.; FERNÁNDEZ, R (coord.) - Historia social y ciencias sociales. Lleida: Milènio, 2001, p. 296 e também de regiões de Flandres e Inglaterra, como expresso em HAEMERS, Jelle; LIDDY, Christian D. - "Popular politics in the late medieval town: York and Bruges". English Historical Review 128 (2012), pp. 771-805. [Em linha]. [Acessado em 19 de janeiro de 2016]. Disponível em http://ehr.oxfordjournals.org/content/128/533/771.full; Marcelo Caetano desenvolve de onde viria essa representação de dois homens bons de cada mester, e infere que seja influência inglesa, devido à falta de organização corporativa na cidade de Lisboa em 1384. CAETANO, Marcelo - A Crise Nacional de 1383$1385 \ldots$, pp. 134-140.
} 
mesmo em Portugal ${ }^{53}$, mas fica destacado o fato de que ele já existira na própria cidade de Lisboa no fim do século XIII, como foi exposto anteriormente. Essa cultura política de participação nas deliberações do poder local se perpetuou entre os mesteirais olissiponenses durante quase uma centúria, o que pode ser considerado uma continuidade calcada na própria experiência social comum que esse grupo vivenciou durante a totalidade dos Trezentos, o que levou a uma ação coletiva como um conjunto unido.

\section{Considerações finais}

O objetivo do presente artigo foi apresentar o contexto no qual os mesteirais participaram das assembleias concelhias lisboetas no decorrer do século XIV, até o começo da Crise Dinástica de Avis. Buscamos identificar, a partir da documentação que chegou até nós, quais foram os assuntos nos quais os trabalhadores de ofícios mecânicos estavam presentes e, por fim, intentamos apresentar uma síntese interpretativa sobre a lógica política que envolvia esses eventos.

Em um período de uma crise que atravessava todas as esferas da vida, os trabalhadores urbanos da Lisboa medieval estavam marginalizados do poder concelhio. Apesar da efêmera experiência de inserção no fim do século XIII, a centúria apresentou que o governo local se pautava em um processo de elitização da prática administrativa. O que buscamos apresentar aqui é que essa oligarquização, apesar de intensa e destacada, jamais foi conclusiva, e as relações de poder possuíam tensões nas quais os mesteirais lutavam para serem atores ativos no palco do governo da cidade, não só durante a Crise Dinástica de Avis, mas por todo o Trezentos ${ }^{54}$.

Enfim, as revoltas das décadas de 1370 e 1380 e o protagonismo dos mesteirais lisboetas na ascensão de D. João, Mestre de Avis, ao trono português são a culminância de um processo histórico de resistência que é gestado na sociedade portuguesa por

\footnotetext{
${ }^{53}$ Especificamente, na cidade de Évora, alguns anos antes do ocorrido em Lisboa, já existia um "concelho meúdo" que, pelo teor dos privilégios enviados pela carta enviada por D. João Mestre de Avis, já contava com uma certa organização dos mesteirais da cidade. SILVA, Leonel José Miguel da - "Da época da Revolução de 1383”. História e Sociedade 2-3, 1 de Janeiro de 1979, pp. I-III.

${ }^{54}$ COELHO, Maria Helena da Cruz - "No palco e nos bastidores do Poder Local...", p. 61.
} 
Os mesteirais e o concelho de Lisboa durante o século XIV: um esboço de síntese (I300-I383) • Bruno Marconi da Costa

quase um século. Podemos apontar a hipótese de que a marginalização dos mesteirais do processo deliberativo foi uma das diversas causas que os levaram às ruas com o intuito de reivindicar perante o regente, com sucesso, a garantia de uma voz política institucionalizada na governação da cidade. No século seguinte, a oligarquia de Lisboa e de outras cidades que seguiram seu exemplo - não tardou em responder a essas demandas. Usando espaços privilegiados como as cortes, buscaram um novo afastamento dos mesteirais dos processos deliberativos, chegando a produzir verdadeiros "manifestos anti-mesteirais" 55 . Com isso, é instituída a Casa dos Vinte e Quatro, um espaço exclusivo para os procuradores dos mesteres proporem linhas de rumo para o governo local sem causar tensões com a oligarquia camarária.

${ }^{55}$ SOUSA, Armindo de - "1325-1480". in MATTOSO, José (org.) - História de Portugal. A Monarquia Feudal. Lisboa: Estampa, 1997, pp. 412-423. 
Os mesteirais e o concelho de Lisboa durante o século XIV: um esboço de síntese (1300-1383) • Bruno Marconi da Costa

\section{Referências bibliográficas:}

\section{Fontes manuscritas}

AML-AH, Livro I de Sentenças, n. 3

A.N.T.T., Mosteiro de S. Dinis de Odivelas, liv. 19, fl. 6-8.

A.N.T.T., Livro I do Hospital do Conde D. Pedro, n. 34 (cópia).

A.N.T.T., Gav. XIII, maç. 1, n. 25 e Livro $2^{\circ}$ dos Direitos Reais, fl. 272v.

\section{Fontes impressas}

BRANDÃO, Frei Francisco - "ESCRITVRA XVIII". in Monarchia Lusitana. Quinta Parte. Lisboa: Officina de Paulo Craeesbeck, 1650, fls. 314v-315v.

DOCUMENTOS PARA A HISTÓRIA DA CIDADE DE LISBOA. Livro I de Místicos de Reis: Livro II dos Reis D. Dinis, D. Afonso IV, D. Pedro I. Lisboa: Câmara Municipal de Lisboa, 1947.

DOCUMENTOS PARA A HISTÓRIA DA CIDADE DE LISBOA. Livro de Místicos do Rei D. Fernando. Lisboa: Câmara Municipal de Lisboa, 1948.

LOPES, Fernão - Crónica de D. Fernando. Biblioteca de Clássicos Portuguezes. Lisboa: Escriptorio, 1895.

\section{Estudos}

CAETANO, Marcello - "Prefácio". in LANGHANS, Franz-Paul - A antiga Organização dos Mesteres da Cidade de Lisboa. Lisboa, 1942, pp. XI-LXXV.

- A administração municipal de Lisboa durante a $1^{a}$ dinastia. Lisboa: Academia Portuguesa da História, 1981.

- A Crise Nacional de 1383-1385. Subsídios para o seu estudo. Lisboa: Verbo, s.d.

CASTRO, Armando - A Evolução Económica de Portugal dos séculos XII ao XV. Lisboa: Portugália, 1966.

COELHO, António Borges - A Revolução de 1383. Lisboa: Seara Nova, 1977. 
Os mesteirais e o concelho de Lisboa durante o século XIV: um esboço de sintese (1300-1383) - Bruno Marconi da Costa

COELHO, Maria Helena da Cruz - "As confrarias medievais portuguesas: espaços de solidariedades na vida e na morte". in Atas da XIX Semana de Estudios Medievales. Confradías, gremios, solidaridades en la Europa Medieval. Estella: Gobierno de Navarra, Departamento de Educación y Cultura, 1992, pp. 149-183.

- "O Estado e as Sociedades Urbanas". in COELHO, Maria Helena da CRUZ; HOMEM, Armando Luís de Carvalho; ALMEIDA, Armando Justino - A Génese do Estado Moderno em Portugal. Ciclo temático de conferências organizado pela Universidade Autónoma de Lisboa no ano lectivo de 1996/1997. Lisboa: Universidade Autónoma Editora, 1997, pp. 269-292.

- "O povo - a identidade e a diferença no trabalho". in MARQUES, A. H. de Oliveira; SERRÃO, Joel (dir.) e COELHO, Maria Helena da Cruz; HOMEM, Armando Luís de Carvalho (coord.) - Nova História de Portugal. Vol. III. Portugal em Definição de Fronteiras. Lisboa: Presença, 1998, pp. 252-308.

- "No palco e nos bastidores do Poder Local". in FONSECA, Fernando Taveira da (dir.) - O poder local em tempo de Globalização. Uma história e um futuro. Coimbra: Centro de Estudos e Formação Autárquica, 2005, pp. 49-74.

- "Municipal Power". in MATTOSO, José (dir.) - Historiography of Medieval Portugal (1950-2010). Lisboa: Instituto de Estudos Medievais, 2011, pp. 209-230.

COELHO, Maria Helena da Cruz; MAGAlHÃES, Joaquim Romero - $O$ poder concelhio. Das origens às cortes constituintes. Coimbra: Centro de Estudos e Formação Autárquica, 1986.

CORTESÃO, Jaime - Os factores democráticos na formação de Portugal. Lisboa: Livros Horizonte, 1984.

COSTA, Adelaide Pereira Milàn da - “Traços da Interacção Conflitual na Sociedade Portuense de Quatrocentos". in Actas das Jornadas Inter e Pluridisciplinares. A Cidade, vol. 1, Lisboa: Universidade Aberta, 1993, pp. 155-164.

- “A cultura política em ação. Diálogos institucionais entre a Coroa e os centros urbanos em Portugal no século XIV”. in En la España Medieval vol. 36 (2013), pp. 929. 
Os mesteirais e o concelho de Lisboa durante o século XIV: um esboço de síntese (1300-1383) • Bruno Marconi da Costa

COSTA, Bruno Marconi da - A burguesia concelhia da Lisboa de D. Dinis - um estudo comparativo das suas relações com o poder monárquico (1279-1325). Rio de Janeiro: Universidade Federal do Rio de Janeiro, 2013. Dissertação de Mestrado. Disponível em www.academia.edu/3997194/A_burguesia_concelhia_da_Lisboa_de_D._Dinis_um_es tudo_comparativo_de_suas_relações_com_o_poder_monárquico_1279-1325_ - "A experiência social dos mesteirais medievais portugueses - uma abordagem thompsoniana". Roda da Fortuna. Revista Eletrônica sobre Antiguidade e Medievo vol. 3, 1 (2014), pp. 221-241.

CUNHAL, Álvaro - As Lutas de Classes em Portugal nos Fins da Idade Média. Lisboa: Estampa, 1980.

FARELO, Mário Sérgio - A Oligarquia Camarária de Lisboa (1325-1433). Lisboa: Faculdade de Letras da Universidade de Lisboa, 2008. Tese de Doutoramento.

FERRO, Maria José Pimenta - “A Revolta dos Mesteirais de 1383”. in Actas das III Jornadas Arqueológicas. Lisboa: Associação dos Arqueólogos Portugueses, 1978, pp. 359-363.

- Pobreza e morte em Portugal na Idade Média. Lisboa: Presença. 1989.

- "Ricos y Pobres en un Siglo de Crisis". Edad Media - Revista de Historia 4 (2001), pp. 23-36.

GONÇALVES, Iria - "Na Ribeira de Lisboa, em finais da Idade Média”. in Um Olhar sobre a Cidade Medieval. Cascais: Patrimonia, 1996, pp. 61-75.

HAEMERS, Jelle - "Ad petitionem burgensium. Petitions and peaceful resistane of craftsmen in Flanders and Mechelen (13th-16th centuries)". in TELECHEA, J.; BOLUMBURU, B; HAEMERS, J. (ed) - Los grupos populares en la ciudad medieval europea. La Rioja: Instituto de Estudios Riojanos, 2014, pp. 371-394.

HAEMERS, Jelle; LIDDY, Christian D. - "Popular politics in the late medieval town: York and Bruges”. English Historical Review 128 (2012), pp. 771-805 [Em linha]. Disponível em http://ehr.oxfordjournals.org/content/128/533/771.full 
Os mesteirais e o concelho de Lisboa durante o século XIV: um esboço de síntese (1300-1383) • Bruno Marconi da Costa

HESPANHA, António Manuel - Panorama Histórico da Cultura Jurídica Europeia. Sintra: Europa-América, 1997.

LANGHANS, Franz-Paul de Almeida - "As Antigas Corporações dos ofícios mecânicos e a Câmara de Lisboa". in Separata de Revista Municipal (Lisboa) 7, 8 e 9. Lisboa: Câmara Municipal, 1942, pp. 3-31.

- As Corporações dos Ofícios Mecânicos. Subsídios para a sua História. Vol. I, Lisboa, 1943.

- A Casa dos Vinte e Quatro de Lisboa. Subsídios para a sua História. Lisboa, 1948.

MARQUES, A. H. de Oliveira - A sociedade medieval portuguesa. Lisboa: Sá da Costa, 1976.

- Portugal na Crise dos séculos XIV e XV. Lisboa: Presença, 1987.

- Novos Ensaios de História Medieval Portuguesa. Lisboa: Presença, 1988.

MARQUES, A. H. OLIVEIRA; SERRÃO, Joel (dir.) e COELHO, Maria Helena da Cruz; HOMEM, Armando Luís de Carvalho (coord.) - Nova História de Portugal. Vol. III. Portugal em Definição de Fronteiras. Lisboa: Presença, 1998.

MARTINS, Miguel Gomes - "O Concelho de Lisboa durante a Idade Média. Homens e Organização Municipal (1179-1383). in Cadernos do Arquivo Municipal de Lisboa. Lisboa: Câmara Municipal. Série I, 7 (2004), pp. 64-110.

MATTOSO, José - "Contrastes entre Cidade e o Campo"; "Luta de classes?". in SARAIVA, José Hermano (dir) - História de Portugal. Lisboa: Alfa, 1983, pp. 159199.

- (org) História de Portugal. A Monarquia Feudal. Lisboa: Estampa, 1997.

- "Revoltas e Revoluções na Idade Média Portuguesa". in Naquele tempo. Ensaios de história medieval. Lisboa: Círculo de Leitores, 2009, pp. 409-425. 
Os mesteirais e o concelho de Lisboa durante o século XIV: um esboço de sintese (1300-1383) - Bruno Marconi da Costa

MELO, Arnaldo Rui Azevedo de Sousa - Trabalho e Produção em Portugal na Idade Média: O Porto, c. 1320 - c. 1415. Braga: Universidade do Minho, 2009. Tese de Doutoramento.

- “Os mesteirais no governo urbano do Porto nos séculos XIV e XV”. in SOLORZANO TElECHEA, J. A.; BOLUMBURU, B. A. (coord.) - La Gobernanza de la ciudad europea en la Edad Media, Logroño: Centro de Estudios Riojanos, 2011, pp. 323-347.

- "Os mesteirais e o poder concelhio nas cidades medievais portuguesas (séculos XIV e XV)”. Edad Media. Revista de Historia 14 (2013), pp. 149-170.

MONSALVO ANTÓN, José María - "Los artesanos y la política en la Castilla medieval. Hipótesis acerca de la ausencia de las corporaciones de oficio de las instituiciones de gobierno urbano". in CASTILLO, S.; FERNÁNDEZ, R (coord.) Historia social y ciencias sociales. Lleida: Milènio, 2001, pp. 291-319.

PRADALIÉ, Gérard - Lisboa: da Reconquista ao fim do século XIII. Lisboa: Palas, 1975.

SÉRGIO, António - Breve interpretação da História de Portugal. Lisboa: Livraria Sá da Costa, 1977.

SERRÃO, Joel - O Carácter Social da Revolução de 1383. Lisboa: Livros Horizonte, 1978.

SILVA, Carlos Guardado da - Lisboa Medieval. A organização e estruturação do espaço urbano. Lisboa: Colibri, 2008.

SILVA, Leonel José Miguel da - "Da época da Revolução de 1383". História e Sociedade 2-3, 1 de janeiro de 1979, pp. I-III.

SOUSA, Armindo de - “1325-1480”. in MATTOSO, José (org.) - História de Portugal. A Monarquia Feudal. Lisboa: Estampa, 1997, pp. 412-423. 
Os mesteirais e o concelho de Lisboa durante o século XIV: um esboço de sintese (1300-1383) • Bruno Marconi da Costa

THOMPSON, E. P. - A Miséria da Teoria ou um planetário de erros: uma crítica ao pensamento de Althusser. Rio de Janeiro: Zahar, 1981.

TILLY, Charles - From Mobilization to Revolution. Michigan: CRSO Working Paper, 1977.

VIEGAS, Valentino - Lisboa, A Força da Revolução (1383-1385). Lisboa: Livros Horizonte, 1985.

\section{COMO CITAR ESTE ARTIGO}

\section{Referência electrónica:}

COSTA, Bruno Marconi da - "Os mesteirais e o concelho de Lisboa durante o século XIV : um esboço de síntese (1300-1383)”. Medievalista 21 (Janeiro-Junho 2017). [Em linha] [Consultado dd.mm.aaaa]. Disponível em http://www2.fcsh.unl.pt/iem/medievalista/MEDIEVALISTA21/costa2105.html ISSN 1646-740X.

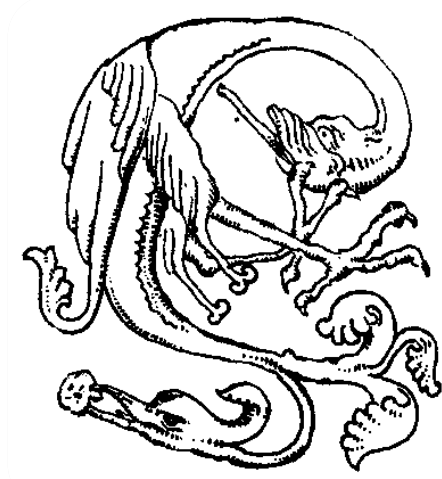

